\title{
Regulators of epithelial mesenchymal transition in pancreatic cancer
}

\author{
Shin Hamada ${ }^{1}$, Kennichi Satoh ${ }^{2}$, Atsushi Masamune ${ }^{1}$ and Tooru Shimosegawa' \\ ' Division of Gastroenterology, Tohoku University Graduate School of Medicine, Sendai, Miyagi, Japan \\ 2 Division of Cancer stem cell, Miyagi Cancer Center Research Institute, Natori, Miyagi, Japan
}

\author{
Edited by: \\ Atsushi Masamune, Tohoku \\ University Graduate School of \\ Medicine, Japan \\ Reviewed by: \\ R. John MacLeod, Queen's \\ University, Canada \\ Kyoko Shimizu, Tokyo Women's \\ Medical University, Japan \\ *Correspondence: \\ Shin Hamada, Division of \\ Gastroenterology, Tohoku University \\ Graduate School of Medicine, \\ 1-1 Seiryo-machi Aobaku, Sendai, \\ Miyagi, 980-8574, Japan. \\ e-mail: hamadas@med.tohoku.ac.jp
}

\begin{abstract}
Pancreatic cancer is a leading cause of cancer-related death due to its invasive nature. Despite the improvement of diagnostic strategy, early diagnosis of pancreatic cancer is still challenging. Surgical resection is the only curative therapy, while vast majority of patients are not eligible for this therapeutic option. Complex biological processes are involved in the establishment of invasion and metastasis of pancreatic cancer and epithelial-mesenchymal transition (EMT) has been reported to play crucial role. EMT is part of the normal developmental processes which mobilizes epithelial cells and yields mesenchymal phenotype. Deregulation of EMT inducing molecules in pancreatic cancer is reported, such as multiple cytokines, growth factors and downstream transcriptional factors. In addition to these molecules, non-coding RNA including miRNA also contributes to EMT. EMT of cancer cell also correlates with cancer stem cell (CSC) properties such as chemoresistance or tumorigenicity, therefore these upstream regulators of EMT could be attractive therapeutic targets and several candidates are examined for clinical application. This review summarizes recent advances in this field, focusing the regulatory molecules of EMT and their downstream targets. Further understanding and research advances will clarify the cryptic mechanism of cancer metastasis and delineate novel therapeutic targets.
\end{abstract}

Keywords: EMT, pancreatic cancer, BMP, MSX2, miR-126

\section{INTRODUCTION}

Epithelial-mesenchymal transition (EMT) is a normal cellular function which is indispensable during developmental processes such as gastrulation or neural crest cell migration (Pla et al., 2001; Nakaya and Sheng, 2008). However, pancreatic cancer cells misuse this machinery for their invasion toward surrounding tissue and dissemination into distant organs (Rhim et al., 2012). Since invasion and metastasis are the key step for untreatable disease, numerous approaches have been made to prevent EMT of pancreatic cancer cells. Unfortunately, these efforts have not yet conquered the EMT of pancreatic cancer cells due to the complex, cryptic mechanisms involved in this biological process.

Several cytokines and growth factors are reported to induce EMT in pancreatic cancer cells. These factors are derived from cancer cell itself (autocrine) or stromal cell (paracrine). For example, transforming growth factor $\beta$ (TGF $\beta$ ) or its family member bone morphogenetic protein (BMP) is reported to cause cellular morphological changes and altered expression of epithelial markers (Fensterer et al., 2004; Hamada et al., 2007). In addition, treatment of pancreatic cancer cells with vascular endothelial growth factor (VEGF) also promotes EMT in pancreatic cancer cells (Yang et al., 2006). These cytokines and growth factors utilize wide variety of receptors and downstream signaling molecules which synergistically or redundantly contribute to the tumor progression.

As a result of the cumulative gene mutations which amplify oncogenic signal, aberrant activation of several signaling pathways are observed in pancreatic cancer cells. Up to $95 \%$ of pancreatic cancer harbors constitutively active mutation of $K$-ras oncogene (Furukawa et al., 2006), which leads to the activation of downstream signals for unlimited cellular proliferation. On the other hand, specific gene deletion results in the defect of tumor suppressive signal such as Smad4 deletion, which is observed in $50 \%$ of pancreatic cancer (Maitra and Hruban, 2008). Alteration of these signaling pathways also contributes to the EMT induction in pancreatic cancer cells.

Tumor microenvironment also influences the biological behavior of pancreatic cancer. The characteristic feature of pancreatic cancer tissue is dense stroma surrounding tumor cells which is called desmoplastic reaction (Mahadevan and Von Hoff, 2007). The existence of desmoplastic reaction is reported to contribute to pancreatic cancer progression. Recent research identified a significant role of the tumor stromal cells in pancreatic cancer such as protection from chemotherapeutic agents (Muerkoster et al., 2004) or metastasis-promoting role (Xu et al., 2010). Based on these findings, tumor stromal cells are attracting interest as a novel therapeutic target of pancreatic cancer.

Recent advances in the cancer research field identified an additional regulatory molecule of cellular functions. MicroRNA is a member of non-coding RNA consists of 20-23 nucleotide which targets $3^{\prime}$ UTR sequence of mRNA for translational repression and destabilization (Farazi et al., 2011). Several reports indicate that microRNA could orchestrate biological processes by targeting hundreds of target mRNAs, including cancer cell invasion and 
metastasis (Sureban et al., 2011). There are several microRNAs which contribute to pancreatic cancer cell migration and invasion whose expression levels correlate with patients' prognosis (Ali et al., 2010a,b; Giovannetti et al., 2010).

These lines of evidences partially uncovered the complex machinery which keep invasive growth of pancreatic cancer cells. Dissecting the detailed mechanism of EMT in cancer cells will elucidate novel therapeutic targets against invasion and metastasis. Following sections describe current knowledge and future perspectives in this field.

\section{EMT-INDUCING CYTOKINES AND GROWTH FACTORS}

TGF $\beta$ is a characteristic cytokine which possesses distinct effects on cellular morphology and proliferation. TGF $\beta$ suppresses cellular proliferation accompanied by the induction of cell cycle regulator $p 21 / w a f 1$, whose induction requires intact Smad4 (Grau et al., 1997). On the other hand, TGF $\beta$ causes down-regulation of epithelial marker E-cadherin (Bardeesy et al., 2006) whose expression attenuates invasive growth of pancreatic cancer cells (Furuyama et al., 2000). Since TGF $\beta$ is enriched in plasma or other extracellular sources (Labelle et al., 2011), this cytokine is considered to be an important inducer of EMT during cancer progression. Similarly, a TGF $\beta$ family member BMP4 which phosphorylates different Smad (Smad1, 5 and 8) from TGF $\beta$ (Smad2 and 3) also induces EMT in pancreatic cancer cells via the induction of MSX2 (Hamada et al., 2007; Gordon et al., 2009). Interestingly, BMP4 also harbors growth inhibitory properties accompanied by the induction of cell cycle regulator $p 21 /$ waf1 (Kleeff et al., 1999; Hamada et al., 2009), suggesting redundant roles of these family members which affect pancreatic cancer progression.

Another growth factor is involved in the EMT induction of pancreatic cancer. VEGF is a potent angiogenic factor which stimulates endothelial cell proliferation and migration (Eilken and Adams, 2010). A characteristic tissue structure of pancreatic cancer, the desmoplastic reaction, hampers efficient blood perfusion which gives rise to increased hypoxia within the tumor. Hypoxic condition stabilizes hypoxia-inducible factor $1 \alpha$ (HIF1 $\alpha)$ which promotes the transcription of VEGF mRNA (Dery et al., 2005). VEGF also affects cellular morphology of pancreatic cancer cells featured by the loss of polarity, loose cell to cell contact or decreased expression of the epithelial markers E-cadherin and plakoglobin which is in accordance with EMT induction (Yang et al., 2006).

Combination of multiple cytokines and growth factors depicts synergistic effects in EMT induction. Fibroblast growth factor 2 (FGF-2) contributes to the EMT induction in transformed epithelial cells as a downstream effector of $\mathrm{HOXB7}$, a homeodomain protein which is overexpressed in breast cancer (Wu et al., 2006). Combined treatment of epithelial cells using recombinant FGF-2 and TGF $\beta$ further enhances the migratory phenotype (Shirakihara et al., 2011). This effect is mediated by the altered expression of FGF receptor subtype by TGF $\beta$ which sensitizes cells to FGF stimuli. Contribution of multiple cytokines and growth factors during EMT could overwhelm the effect of single-target therapy and enable redundant promotion of invasive growth.

\section{EMT AND INTRACELLULAR SIGNALING}

As mentioned in the previous section, pancreatic cancer cells are under the influence of various cytokines and growth factors. These extracellular stimuli activate intracellular signaling molecules which contribute to the invasive phenotype of cancer cells. Among these signaling molecules, the role of extracellular signal-regulated kinase (ERK) pathway is well characterized during EMT. Treatment of pancreatic cancer cell line Panc- 1 by TGF $\beta$ leads to the increased phosphorylation of ERK which is indispensable for the EMT induction by TGF $\beta$ (Ellenrieder et al., 2001). Since ERK is activated by its upstream regulator Ras/Raf/MEK pathway (Lopez-Chavez et al., 2009), activating mutation of Kras could elevate the baseline activity of ERK pathway for further amplification of TGF $\beta$ signal.

Besides the Ras/Raf/MEK/ERK pathway, inflammatory signal-related pathway also plays important role for pancreatic carcinogenesis. Previous report suggested that addition of chronic inflammation by caerulein in genetically engineered mice model expressing pancreas-specific Kras G12D significantly enhanced the pancreatic cancer incidence (Guerra et al., 2007). Among those inflammatory signal-related molecules, nuclear factor kappa B (NFкB) plays aggravating role by inducing pro-inflammatory cytokines which sustains chronic inflammation within tumor (Ling et al., 2012). NFאB also promotes EMT in pancreatic cancer cells by inducing mesenchymal marker Vimentin and EMT-related transcriptional factor ZEB1 (Maier et al., 2010).

Aberrant activation of other signaling pathway is reported in pancreatic cancer. Notch is a cell surface receptor which regulates cell fate determination and differentiation during embryonic stage whose activation is also seen in pancreatic cancer (Kimura et al., 2007). Acquisition of gemcitabine-resistant phenotype of pancreatic cancer cells is accompanied by the elevated notch activity, whose silencing by siRNA attenuates the EMT phenotype such as vimentin, ZEB1, Slug, and Snail expression (Wang et al., 2009). Another signaling pathway, sonic hedgehog pathway is also involved in pancreatic carcinogenesis whose original role is an endodermal-mesodermal cross-talk during gut development (van den Brink, 2007). Inhibition of hedgehog pathway by several agents such as epigallocatechin-3-gallate or IPI-269609 abrogated EMT phenotype of pancreatic cancer cells (Feldmann et al., 2008; Tang et al., 2012). Targeting these signaling pathways could be an effective therapy for EMT inhibition, but complex cross-talk between multiple pathways could lead to the resistance against single-agent therapy.

\section{EMT AND TUMOR MICROENVIRONMENT}

The tumor microenvironment itself could exert EMT-promoting effects. Hypoxia is a characteristic feature in pancreatic cancer tissue, and besides the VEGF production, hypoxia alters intracellular signals by up-regulating HIF1 $\alpha$. Twist is a transcriptional factor involved in the EMT of pancreatic cancer cells (Satoh et al., 2008) and HIF $1 \alpha$ induces its expression (Sun et al., 2009). This is a direct effect of hypoxia on cancer cells similar to the adaptation to the hypoxic conditions (Pasteur effect).

When considering the cellular component within pancreatic cancer stroma, the pancreatic stellate cells (PSC) should be 
emphasized as a central regulator of fibrosis. (Masamune and Shimosegawa, 2009; Masamune et al., 2009; Erkan et al., 2012) PSCs contribute to the formation of desmoplastic reaction by producing extracellular matrix proteins such as fibronectin or collagen (Bachem et al., 2005). These matrix proteins yield growth stimulatory effects and EMT promotion (Kanno et al., 2008) on pancreatic cancer cells which could be recognized as preconditioning of cancer cells for metastasis.

Another report suggested that PSCs also contribute to establish metastatic site in vivo in collaboration with cancer cells (Xu et al., 2010). The detailed mechanism for this phenomenon remains elusive, but recent researches clarified the part of the picture. Indirect co-culture of PSCs promotes EMT phenotype in pancreatic cancer cells independently of TGF $\beta$ (Kikuta et al., 2010). This treatment also enhanced the cancer stem cell (CSC) related genes' expression and spheroid formation, a hallmark of CSC function (Hamada et al., 2012a), suggesting novel regulatory mechanism of PSCs in cancer metastasis. Since PSC itself is a non-transformed cell, inhibition of PSC function might be accomplished without acquiring therapy resistance. Targeting cancer supporting cells could be a promising therapeutic option. For the inhibition of PSC function, several signaling pathways are identified such as peroxisome proliferator-activated receptor-gamma, mitogen-activated protein kinases, and reactive oxygen species which could be modulated pharmaceutically (Masamune and Shimosegawa, 2009).

\section{EMT-INDUCING microRNA}

Recent advances in cancer research field identified novel regulatory molecule in EMT. MicroRNA is a member of non-coding RNA which targets hundreds of target mRNA, thereby orchestrating cellular functions including EMT. Until now, several microRNAs are reported to be involved in the regulation of pancreatic cancer cell motility and invasion. MiR-21 is highly expressed in pancreatic cancer compared with normal tissue, and introduction of miR-21 precursor results in increased cellular proliferation and invasion accompanied by the induction of matrix metalloproteinase-2 and -9 (Moriyama et al., 2009). Furthermore, miR-21 also contributes to the resistance against gemcitabine and correlates with patient's survival (Giovannetti et al., 2010). Expression levels of microRNAs are measurable in plasma samples, and their clinical application is expected. Serum miR-21 expression level is elevated in patient with pancreatic cancer and correlated with poor survival, which indicates miR-21 could be an efficient biomarker of pancreatic cancer (Ali et al., 2010a,b).

In contrast to the miR-21, EMT-inhibiting microRNA is also identified by comprehensive analysis. By comparing the microRNA expression profiles in invasive ductal adenocarcinoma



FIGURE 1 | A schematic view of EMT regulators in pancreatic cancer development. Secreted cytokines such as TGF $\beta$ or BMP activates intracellular signal which leads to the EMT induction. Activating mutation such as Kras G12D constitutively stimulates intracellular signal and amplifies extracellular signal. Endogenous alteration of microRNA expression modifies cancer cell function. Stromal cells including PSCs establish protective microenvironment for cancer cells such as desmoplasia. 
with intraductal papillary mucinous neoplasm, the miR-126 was identified as a significantly down-regulated microRNA in invasive ductal adenocarcinoma (Hamada et al., 2012b). Database analysis identified that miR-126 potentially targets disintegrin and metalloproteinase domain-containing protein 9 (ADAM9), which is highly expressed in pancreatic cancer (Grutzmann et al., 2004). Expression of miR-126 and ADAM9 were mutually exclusive, and re-expression of miR-126 attenuated pancreatic cancer cell migration and invasion (Hamada et al., 2012b). These findings suggest the multimodal regulation of EMT during pancreatic cancer progression.

\section{CONCLUSION}

This review summarized the current knowledge about the regulatory mechanisms of EMT. The schematic view of these regulators of EMT is shown in Figure 1. Inhibition of specific cytokines, growth factors or signaling pathways met their limitations for clinical applications due to the redundant regulation of EMT in pancreatic cancer. Targeting normal cells such as endothelial cells, immune cells, or stromal cells which sustain cancer microenvironment would be novel therapeutic targets against cancer invasion and metastasis. In addition to this concept, a comprehensive regulator of cellular function, microRNA could be a powerful tool in regulating metastasispromoting microenvironment. Further understanding about the EMT regulation will provide efficient therapy against pancreatic cancer.

\section{ACKNOWLEDGMENTS}

This work was supported in part by Grant-in-aid 24790674, 23390194, and 23591008 from the Ministry of Education, Science, Sports, and Culture in Japan.

\section{REFERENCES}

Ali, S., Ahmad, A., Banerjee, S., Padhye, S., Dominiak, K., Schaffert, J. M., Wang, Z., Philip, P. A., and Sarkar, F. H. (2010a). Gemcitabine sensitivity can be induced in pancreatic cancer cells through modulation of miR-200 and miR-21 expression by curcumin or its analogue CDF. Cancer Res. 70, 3606-3617.

Ali, S., Almhanna, K., Chen, W., Philip, P. A., and Sarkar, F. H. (2010b). Differentially expressed miRNAs in the plasma may provide a molecular signature for aggressive pancreatic cancer. Am. J. Transl. Res. 3, 28-47.

Bachem, M. G., Schunemann, M., Ramadani, M., Siech, M., Beger, H., Buck, A., Zhou, S., SchmidKotsas, A., and Adler, G. (2005). Pancreatic carcinoma cells induce fibrosis by stimulating proliferation and matrix synthesis of stellate cells. Gastroenterology 128, 907-921.

Bardeesy, N., Cheng, K. H., Berger, J. H., Chu, G. C., Pahler, J., Olson, P., Hezel, A. F., Horner, J., Lauwers, G. Y., Hanahan, D., and DePinho, R. A. (2006). Smad4 is dispensable for normal pancreas development yet critical in progression and tumor biology of pancreas cancer. Genes Dev. 20, 3130-3146.

Dery, M. A., Michaud, M. D., and Richard, D. E. (2005). Hypoxiainducible factor 1 , regulation by hypoxic and non-hypoxic activators. Int. J. Biochem. Cell Biol. 37, 535-540.

Eilken, H. M., and Adams, R. H. (2010). Dynamics of endothelial cell behavior in sprouting angiogenesis. Curr. Opin. Cell Biol. 22, 617-625.

Ellenrieder, V., Hendler, S. F., Boeck, W., Seufferlein, T., Menke, A., Ruhland, C., Adler, G., and Gress,
T. M. (2001). Transforming growth factor betal treatment leads to an epithelial-mesenchymal transdifferentiation of pancreatic cancer cells requiring extracellular signalregulated kinase 2 activation. Cancer Res. 61, 4222-4228.

Erkan, M., Adler, G., Apte, M. V., Bachem, M. G., Buchholz, M., Detlefsen, S., Esposito, I., Friess, H., Gress, T. M., Habisch, H. J., Hwang, R. F., Jaster, R., Kleeff, J., Kloppel, G., Kordes, C., Logsdon, C. D., Masamune, A., Michalski, C. W., Oh, J., Phillips, P. A., Pinzani, M., Reiser-Erkan, C., Tsukamoto, H., and Wilson, J. (2012). StellaTUM: current consensus and discussion on pancreatic stellate cell research. Gut 61, 172-178.

Farazi, T. A., Spitzer, J. I., Morozov, P., and Tuschl, T. (2011). miRNAs in human cancer. J. Pathol. 223, 102-115.

Feldmann, G., Fendrich, V., McGovern, K., Bedja, D., Bisht, S., Alvarez, H., Koorstra, J. B., Habbe, N., Karikari, C., Mullendore, M., Gabrielson, K. L., Sharma, R., Matsui, W., and Maitra, A. (2008). An orally bioavailable smallmolecule inhibitor of Hedgehog signaling inhibits tumor initiation and metastasis in pancreatic cancer. Mol. Cancer Ther. 7, 2725-2735.

Fensterer, H., Giehl, K., Buchholz, M., Ellenrieder, V., Buck, A., Kestler, H. A., Adler, G., Gierschik, P., and Gress, T. M. (2004). Expression profiling of the influence of RAS mutants on the TGFB1-induced phenotype of the pancreatic cancer cell line PANC-1. Genes Chromosomes Cancer 39, 224-235.

Furukawa, T., Sunamura, M., and Horii, A. (2006). Molecular mechanisms of pancreatic carcinogenesis. Cancer Sci. 97, $1-7$.

Furuyama, H., Arii, S., Mori, A., and Imamura, M. (2000). Role of E-cadherin in peritoneal dissemination of the pancreatic cancer cell line, panc-1, through regulation of cell to cell contact. Cancer Lett. 157, 201-209.

Giovannetti, E., Funel, N., Peters, G. J., Del Chiaro, M., Erozenci, L. A., Vasile, E., Leon, L. G., Pollina, L. E., Groen, A., Falcone, A., Danesi, R., Campani, D., Verheul, H. M., and Boggi, U. (2010). MicroRNA-21 in pancreatic cancer: correlation with clinical outcome and pharmacologic aspects underlying its role in the modulation of gemcitabine activity. Cancer Res. 70, 4528-4538.

Gordon, K. J., Kirkbride, K. C., How, T., and Blobe, G. C. (2009). Bone morphogenetic proteins induce pancreatic cancer cell invasiveness through a Smad1-dependent mechanism that involves matrix metalloproteinase-2. Carcinogenesis 30, 238-248.

Grau, A. M., Zhang, L., Wang, W., Ruan, S., Evans, D. B., Abbruzzese, J. L., Zhang, W., and Chiao, P. J. (1997). Induction of p21waf1 expression and growth inhibition by transforming growth factor beta involve the tumor suppressor gene DPC4 in human pancreatic adenocarcinoma cells. Cancer Res. 57, 3929-3934.

Grutzmann, R., Luttges, J., Sipos, B., Ammerpohl, O., Dobrowolski, F., Alldinger, I., Kersting, S., Ockert, D., Koch, R., Kalthoff, H., Schackert, H. K., Saeger, H. D., Kloppel, G., and Pilarsky, C. (2004). ADAM9 expression in pancreatic cancer is associated with tumour type and is a prognostic factor in ductal adenocarcinoma. Br. J. Cancer 90, 1053-1058.

Guerra, C., Schuhmacher, A. J., Canamero, M., Grippo, P. J., Verdaguer, L., Perez-Gallego, L., Dubus, P., Sandgren, E. P., and Barbacid, M. (2007). Chronic pancreatitis is essential for induction of pancreatic ductal adenocarcinoma by K-Ras oncogenes in adult mice. Cancer Cell 11, 291-302.

Hamada, S., Masamune, A., Takikawa, T., Suzuki, N., Kikuta, K., Hirota, M., Hamada, H., Kobune, M., Satoh, K., and Shimosegawa, T. (2012a). Pancreatic stellate cells enhance stem cell-like phenotypes in pancreatic cancer cells. Biochem. Biophys. Res. Commun. 421, 349-354.

Hamada, S., Satoh, K., Fujibuchi, W., Hirota, M., Kanno, A., Unno, J., Masamune, A., Kikuta, K., Kume, K., and Shimosegawa, T. (2012b). MiR-126 acts as a tumor suppressor in pancreatic cancer cells via the regulation of ADAM9. Mol. Cancer Res. 10, 3-10.

Hamada, S., Satoh, K., Hirota, M., Fujibuchi, W., Kanno, A., Umino, J., Ito, H., Satoh, A., Kikuta, K., Kume, K., Masamune, A., and Shimosegawa, T. (2009). Expression of the calcium-binding protein S100P is regulated by bone morphogenetic protein in pancreatic duct epithelial cell lines. Cancer Sci. 100, 103-110.

Hamada, S., Satoh, K., Hirota, M., Kimura, K., Kanno, A., Masamune, A., and Shimosegawa, T. (2007). Bone morphogenetic protein 4 induces epithelialmesenchymal transition through MSX2 induction on pancreatic cancer cell line. J. Cell. Physiol. 213, 768-774. 
Kanno, A., Satoh, K., Masamune, A., Hirota, M., Kimura, K., Umino, J., Hamada, S., Satoh, A., Egawa, S., Motoi, F., Unno, M., and Shimosegawa, T. (2008). Periostin, secreted from stromal cells, has biphasic effect on cell migration and correlates with the epithelial to mesenchymal transition of human pancreatic cancer cells. Int. J. Cancer 122, 2707-2718.

Kikuta, K., Masamune, A., Watanabe, T., Ariga, H., Itoh, H., Hamada, S., Satoh, K., Egawa, S., Unno, M., and Shimosegawa, T. (2010). Pancreatic stellate cells promote epithelialmesenchymal transition in pancreatic cancer cells. Biochem. Biophys. Res. Commun. 403, 380-384.

Kimura, K., Satoh, K., Kanno, A., Hamada, S., Hirota, M., Endoh, M., Masamune, A., and Shimosegawa, T. (2007). Activation of Notch signaling in tumorigenesis of experimental pancreatic cancer induced by dimethylbenzanthracene in mice. Cancer Sci. 98, 155-162.

Kleeff, J., Maruyama, H., Ishiwata, T., Sawhney, H., Friess, H., Buchler, M. W., and Korc, M. (1999). Bone morphogenetic protein 2 exerts diverse effects on cell growth in vitro and is expressed in human pancreatic cancer in vivo. Gastroenterology 116, 1202-1216.

Labelle, M., Begum, S., and Hynes, R. O. (2011). Direct signaling between platelets and cancer cells induces an epithelial-mesenchymallike transition and promotes metastasis. Cancer Cell 20, 576-590.

Ling, J., Kang, Y., Zhao, R., Xia, Q., Lee, D. F., Chang, Z., Li, J., Peng, B., Fleming, J. B., Wang, H., Liu, J., Lemischka, I. R., Hung, M. C., and Chiao, P. J. (2012). KrasG12D-induced IKK2/beta/NF-kappaB activation by IL-1alpha and p62 feedforward loops is required for development of pancreatic ductal adenocarcinoma. Cancer Cell 21, 105-120.

Lopez-Chavez, A., Carter, C. A., and Giaccone, G. (2009). The role of KRAS mutations in resistance to EGFR inhibition in the treatment of cancer. Curr. Opin. Investig. Drugs 10, 1305-1314.
Mahadevan, D., and Von Hoff, D. D. (2007). Tumor-stroma interactions in pancreatic ductal adenocarcinoma. Mol. Cancer Ther. 6, 1186-1197.

Maier, H. J., Schmidt-Strassburger, U., Huber, M. A., Wiedemann, E. M., Beug, H., and Wirth, T. (2010). NF-kappaB promotes epithelialmesenchymal transition, migration and invasion of pancreatic carcinoma cells. Cancer Lett. 295, 214-228.

Maitra, A., and Hruban, R. H. (2008). Pancreatic cancer. Annu. Rev. Pathol. 3, 157-188.

Masamune, A., and Shimosegawa, T. (2009). Signal transduction in pancreatic stellate cells. J. Gastroenterol. 44, 249-260.

Masamune, A., Watanabe, T., Kikuta, K., and Shimosegawa, T. (2009). Roles of pancreatic stellate cells in pancreatic inflammation and fibrosis. Clin. Gastroenterol. Hepatol. 7, S48-S54.

Moriyama, T., Ohuchida, K., Mizumoto, K., Yu, J., Sato, N., Nabae, T., Takahata, S., Toma, H., Nagai, E., and Tanaka, M. (2009). MicroRNA-21 modulates biological functions of pancreatic cancer cells including their proliferation, invasion, and chemoresistance. Mol. Cancer Ther. 8, 1067-1074.

Muerkoster, S., Wegehenkel, K., Arlt, A., Witt, M., Sipos, B., Kruse, M. L., Sebens, T., Kloppel, G., Kalthoff, H., Folsch, U. R., and Schafer, H. (2004). Tumor stroma interactions induce chemoresistance in pancreatic ductal carcinoma cells involving increased secretion and paracrine effects of nitric oxide and interleukin-1beta. Cancer Res. 64, 1331-1337.

Nakaya, Y., and Sheng, G. (2008). Epithelial to mesenchymal transition during gastrulation: an embryological view. Dev. Growth Differ. 50, 755-766.

Pla, P., Moore, R., Morali, O. G., Grille, S., Martinozzi, S., Delmas, V., and Larue, L. (2001). Cadherins in neural crest cell development and transformation. J. Cell. Physiol. 189, 121-132.

Rhim, A. D., Mirek, E. T., Aiello, N. M., Maitra, A., Bailey, J. M., McAllister,
F., Reichert, M., Beatty, G. L., Rustgi, A. K., Vonderheide, R. H., Leach, S. D., and Stanger, B. Z. (2012). EMT and dissemination precede pancreatic tumor formation. Cell 148, 349-361.

Satoh, K., Hamada, S., Kimura, K., Kanno, A., Hirota, M., Umino, J., Fujibuchi, W., Masamune, A., Tanaka, N., Miura, K., Egawa, S., Motoi, F., Unno, M., Vonderhaar, B. K., and Shimosegawa, T. (2008). Up-regulation of MSX2 enhances the malignant phenotype and is associated with twist 1 expression in human pancreatic cancer cells. Am. J. Pathol. 172, 926-939.

Shirakihara, T., Horiguchi, K., Miyazawa, K., Ehata, S., Shibata, T., Morita, I., Miyazono, K., and Saitoh, M. (2011). TGF-beta regulates isoform switching of FGF receptors and epithelialmesenchymal transition. EMBO J. 30, 783-795.

Sun, S., Ning, X., Zhang, Y., Lu, Y., Nie, Y., Han, S., Liu, L., Du, R., Xia, L., He, L., and Fan, D. (2009). Hypoxia-inducible factorlalpha induces Twist expression in tubular epithelial cells subjected to hypoxia, leading to epithelial-tomesenchymal transition. Kidney Int 75, 1278-1287.

Sureban, S. M., May, R., Lightfoot, S. A., Hoskins, A. B., Lerner, M., Brackett, D. J., Postier, R. G., Ramanujam, R., Mohammed, A., Rao, C. V., Wyche, J. H., Anant, S., and Houchen, C. W. (2011). DCAMKL-1 regulates epithelial-mesenchymal transition in human pancreatic cells through a miR-200a-dependent mechanism. Cancer Res. 71, 2328-2338.

Tang, S. N., Fu, J., Nall, D., Rodova, M., Shankar, S., and Srivastava, R. K. (2012). Inhibition of sonic hedgehog pathway and pluripotency maintaining factors regulate human pancreatic cancer stem cell characteristics. Int. J. Cancer 131, 30-40.

van den Brink, G. R. (2007). Hedgehog signaling in development and homeostasis of the gastrointestinal tract. Physiol. Rev. 87, 1343-1375.

Wang, Z., Li, Y., Kong, D., Banerjee, S., Ahmad, A., Azmi, A. S., Ali, S., Abbruzzese, J. L., Gallick, G. E., and Sarkar, F. H. (2009). Acquisition of epithelial-mesenchymal transition phenotype of gemcitabineresistant pancreatic cancer cells is linked with activation of the notch signaling pathway. Cancer Res. 69, 2400-2407.

Wu, X., Chen, H., Parker, B., Rubin, E., Zhu, T., Lee, J. S., Argani, P., and Sukumar, S. (2006). HOXB7, a homeodomain protein, is overexpressed in breast cancer and confers epithelial-mesenchymal transition. Cancer Res. 66, 9527-9534.

$\mathrm{Xu}, \mathrm{Z}$., Vonlaufen, A., Phillips, P. A., Fiala-Beer, E., Zhang, X., Yang, L., Biankin, A. V., Goldstein, D. Pirola, R. C., Wilson, J. S., and Apte, M. V. (2010). Role of pancreatic stellate cells in pancreatic cancer metastasis. Am. J. Pathol. 177, 2585-2596.

Yang, A. D., Camp, E. R., Fan, F., Shen, L., Gray, M. J., Liu, W., Somcio, R., Bauer, T. W., Wu, Y., Hicklin, D. J., and Ellis, L. M. (2006). Vascular endothelial growth factor receptor-1 activation mediates epithelial to mesenchymal transition in human pancreatic carcinoma cells. Cancer Res. 66, 46-51.

Conflict of Interest Statement: The authors declare that the research was conducted in the absence of any commercial or financial relationships that could be construed as a potential conflict of interest.

Received: 08 May 2012; accepted: 19 June 2012; published online: 10 July 2012.

Citation: Hamada S, Satoh K, Masamune $A$ and Shimosegawa $T$ (2012) Regulators of epithelial mesenchymal transition in pancreatic cancer. Front. Physio. 3:254. doi: 10.3389/fphys.2012.00254

This article was submitted to Frontiers in Gastrointestinal Sciences, a specialty of Frontiers in Physiology.

Copyright (c) 2012 Hamada, Satoh, Masamune and Shimosegawa. This is an open-access article distributed under the terms of the Creative Commons Attribution License, which permits use, distribution and reproduction in other forums, provided the original authors and source are credited and subject to any copyright notices concerning any thirdparty graphics etc. 